\title{
Objective evidence that small-fiber polyneuropathy underlies some illnesses currently labeled as fibromyalgia
}

\section{Citation}

Oaklander, Anne Louise, Zeva Daniela Herzog, Heather M. Downs, and Max M. Klein. 2013. "Objective Evidence That Small-Fiber Polyneuropathy Underlies Some Illnesses Currently Labeled as Fibromyalgia." Pain 154 (11) (November): 2310-2316. doi:10.1016/j.pain.2013.06.001.

\section{Published Version}

10.1016/j.pain.2013.06.001

\section{Permanent link}

http://nrs.harvard.edu/urn-3:HUL.InstRepos:34627336

\section{Terms of Use}

This article was downloaded from Harvard University's DASH repository, and is made available under the terms and conditions applicable to Other Posted Material, as set forth at http:// nrs.harvard.edu/urn-3:HUL.InstRepos:dash.current.terms-of-use\#LAA

\section{Share Your Story}

The Harvard community has made this article openly available.

Please share how this access benefits you. Submit a story.

\section{Accessibility}




\title{
Objective evidence that small-fiber polyneuropathy underlies some illnesses currently labeled as fibromyalgia
}

\author{
Anne Louise Oaklander, MD, PhD ${ }^{1,2}$, Zeva Daniela Herzog, BA ${ }^{1}$, Heather Downs, BS $^{1}$, and \\ Max M. Klein, PhD ${ }^{1}$ \\ ${ }^{1}$ Department of Neurology, Massachusetts General Hospital, Harvard Medical School, Boston, \\ Massachusetts, 02114 \\ ${ }^{2}$ Department of Pathology (Neuropathology), Massachusetts General Hospital, Boston, \\ Massachusetts, 02114
}

\begin{abstract}
Fibromyalgia is a common, disabling, syndrome that includes chronic widespread pain plus other diverse symptoms. No specific objective abnormalities have been identified, precluding definitive testing, disease-modifying treatments, and identification of causes. In contrast, small-fiber polyneuropathy (SFPN), despite causing similar symptoms, is definitionally a disease caused by dysfunction and degeneration of peripheral small-fiber neurons. SFPN has established etiologies, some diagnosable and definitively treatable, e.g., diabetes. To evaluate the hypothesis that some patients labeled with "fibromyalgia" have unrecognized SFPN causing their illness symptoms, we analyzed SFPN-associated symptoms, signs, and pathological and physiological markers in 27 fibromyalgia patients and 30 matched normal controls. Fibromyalgia subjects had to satisfy American College of Rheumatology criteria plus present documented evidence of a physician's actual fibromyalgia diagnosis. Study instruments comprised the Michigan Neuropathy Screening Instrument (MNSI), the Utah Early Neuropathy Scale (UENS), distal-leg neurodiagnostic skin biopsies, plus autonomic-function testing (AFT). $41 \%$ of skin biopsies from fibromyalgia subjects vs. 3\% of biopsies from control subjects were diagnostic for SFPN, and MNSI and UENS scores were higher among fibromyalgia than control subjects (all $P \leq 0.001$ ). Abnormal AFTs were equally prevalent suggesting that fibromyalgia-associated SFPN is primarily somatic. Blood tests from all 13 fibromyalgia subjects with SFPN-diagnostic skin biopsies provided insights into etiologies. All glucose tolerance tests were normal, but eight subjects had dysimmune markers, 2 had hepatitis $\mathrm{C}$ serologies, and one family had apparent genetic causality. These findings suggest that some patients with chronic pain labeled as "fibromyalgia" have unrecognized small-fiber polyneuropathy, a distinct disease that can be objectively tested for and sometimes definitively treated.
\end{abstract}

\footnotetext{
(C) 2013 International Association for the Study of Pain. Published by Elsevier B.V. All rights reserved.

Corresponding Author: Anne Louise Oaklander, MD, PhD, Massachusetts General Hospital, Department of Neurology, Nerve Injury Unit, 275 Charles Street, Warren 310, Boston, MA 02114, aoaklander@partners.org, Tel: 617-726-0260, Fax: 617-726-0473. Complete Affiliations of All Authors:

Department of Neurology, Massachusetts General Hospital, 275 Charles Street, Warren 310, Boston, MA 02114

Conflicts of Interest: None

Publisher's Disclaimer: This is a PDF file of an unedited manuscript that has been accepted for publication. As a service to our customers we are providing this early version of the manuscript. The manuscript will undergo copyediting, typesetting, and review of the resulting proof before it is published in its final citable form. Please note that during the production process errors may be discovered which could affect the content, and all legal disclaimers that apply to the journal pertain.
} 


\section{Keywords}

chronic pain; human-subject research; peripheral neuropathy; peripheral nerve; skin biopsy; autonomic function testing

\section{Introduction}

Fibromyalgia syndrome (FMS) is a collection of ill-defined symptoms that includes chronic widespread pain (CWP; defined as $\geq 3$ months of axial, plus left- and right-side, plus upperand lower-body pain [51]). FMS is common, with $1-5 \%$ point prevalence in western countries, affects females 3-4 times more often than males, and conveys high health-care costs $[29 ; 49 ; 50]$. The American College of Rheumatology formulated and revised the diagnostic criteria that raised awareness of FMS and facilitated approval of medications to palliate symptoms [51;52], but the biological causes of FMS remain unknown. Recent interpretations emphasize a biopsychosocial model where "central sensitization" causes painful responses to stress and stimuli. However, the brain-imaging alterations in FMS patients that engendered this hypothesis [17;22] were later reinterpreted as non-specific consequences rather than causal $[21 ; 40 ; 47]$.

Small-fiber polyneuropathy (SFPN) is a neurological cause of CWP. Unlike FMS, SFPN has identifiable pathology, physiology, and causes, and thus is definitionally a disease. SFPN is caused by dysfunction and degeneration of the small-diameter unmyelinated (C-fibers) and thinly myelinated (A-delta) peripheral axons that mediate nociception. Symptoms usually begin distally with foot or leg pain, but advanced cases spread proximally to involve the torso as well. Occasional patients begin with patchy, proximal, or generalized (non-lengthdependent) symptoms caused by attack directed at the neuronal cell-bodies (ganglionopathy/ neuronopathy) [16]. Many SFPN patients also have cardiovascular, gastrointestinal, microvascular, and/or sweating complaints due disturbed efferent effects of somatic and autonomic small-fibers on internal organs, blood vessels, and sweat glands [15;20].

SFPN often remains undiagnosed since CWP complaints are subjective and nonspecific, and patients' strength and reflexes are usually preserved. Diagnostic testing using surface electromyography and nerve conduction study is insensitive to SFPN. The best objective diagnostic tests for SFPN are distal-leg skin biopsy immunolabeled to reveal density of small-fiber epidermal innervation (Level C recommendation by the American Academy of Neurology (AAN), Level A recommendation by the European Federation of Neurological Societies) [8;28], and autonomic function testing (AFT) of cardiovagal, adrenergic, and sudomotor small-fiber function (AAN Level B recommendation) [1;8]. Quantitative sensory testing is not recommended because it relies on subjective report [12]. The best instruments for measuring SFPN symptoms and signs are those applied here. The value of diagnosing SFPN is that sometimes causal etiologies can be identified and even cured. Common causes of SFPN include diabetes, hematological malignancies, autoimmune conditions, infections, toxins (including medications), and mutations [4;9].

SFPN and FMS have symptoms in common-not only multifocal CWP, but also Raynaud's phenomena, dizziness, gastrointestinal and urologic symptoms, fatigue, and headache [4], and many SFPN patients report that their illness had been interpreted as FMS prior to diagnosis of SFPN. Electrodiagnostic testing of 58 FM-labeled patients for large-fiber demyelinating polyneuropathy found neuropathic abnormalities in 33\% [6], and comparing sensory symptoms among 1434 FMS patients and 1623 patients with painful diabetic polyneuropathy identified some commonalities [26]. Several recent abstracts suggest that SFPN and FMS may overlap [41;44;45]. Our discovery of objectively confirmed SFPN in 
59\% of patients with childhood-onset, CWP [37], many originally labeled with FMS, prompted this study.

\section{Subjects and Methods}

\subsection{Study Design and Subject Recruitment}

All procedures and protocols had institutional IRB approval. Sample-size calculations assuming $P=0.05$ indicated that studying 33 subjects per group would have $90 \%$ power to detect a large effect size (0.8) and groups of 25 would have $80 \%$ power, so we planned for groups of 25-30. Recruitment strategies included print and email advertising at MGH and email to MGH's Clinical Research database of $\geq 22,000$ pre-registered people interested in clinical research participation (http://www.rsvpforhealth.partners.org/). No subjects were recruited from any neurology practice or clinic. We digitally searched MGH's medicalrecords to identify fibromyalgia patients to whom we mailed a description of this study through their primary-care provider. We also recruited through fibromyalgia support groups on Facebook and Meetup.com social networking sites. Respondents were telephonescreened for inclusion (see criteria below), medical records confirming prior FMS diagnoses were obtained, and all eligible respondents were invited for study (Figure 1). Asymptomatic volunteers were selected on the basis of demographic characteristics to match the FMS cohort.

Inclusion criteria for all subjects were age at least 18 years and ability to comprehend and execute the protocol. Exclusion criteria comprised inability to give informed consent and contraindication to AFT or skin biopsy. FMS subjects were additionally required to submit medical records that documented a prior independent physician's diagnosis of fibromyalgia, plus they were required to fulfill the American College of Rheumatology (ACR) 2010 diagnostic criteria for FMS as assessed by questionnaire [51]. These require a score $\geq 7$ on the widespread-pain inventory (WPI) plus a score $\geq 5$ on the symptom severity scale (SS) or $3 \leq$ WPI $\leq 6$ if SS $\geq 9$ [51].

\subsection{Data Acquisition}

To quantitate symptoms, consented subjects completed the Michigan Neuropathy Screening Instrument questionnaire (MNSI), which consists of 15 "yes/no" questions on foot sensation including pain, numbness, and sensitivity to temperature [11;34]. For diabetic small-fiber predominant polyneuropathy, the sensitivity of the MNSI was $80 \%$, specificity was $95 \%$, positive predictive value was $97 \%$, and negative predictive value was $74 \%$ [11]. All subjects also underwent targeted neurological examination, which was codified using the Utah Early Neuropathy Scale (UENS), a neurological examination of the lower legs and feet designed to detect small-fiber-predominant sensory neuropathy [43]. It particularly focuses on loss of small-fiber-mediated pin-evoked nociception. To provide additional information about the representativeness of the FMS and control samples, all subjects completed the Beck Depression Inventory (BDI-21) and the Medical Outcomes Study Short Form Health Survey (SF-36). These validated questionnaires have known profiles among FMS patients and normal controls $[2 ; 3 ; 23]$. Subjects were compensated $\$ 100$ plus parking expenses. Data were managed using the Harvard Clinical and Translational Science Center's secure online Research Electronic Data Capture (REDCap) platform [18], and accuracy of data entry was verified.

Neurodiagnostic skin biopsies were processed and analyzed by our accredited clinical diagnostic laboratory according to consensus standards [8;27]. Two or three-mm diameter skin punches were removed from the anesthetized standard distal-leg site. Free-floating 50 $\mu \mathrm{m}$ vertical sections were immunohistochemically labeled against PGP9.5, a pan-neuronal marker (Chemicon, Temecula, CA) to reveal epidermal nerve fibers (ENF) and permit 
standard measurements of their density [4;8;28]. Almost all PGP9.5-immunoreactive epidermal neurites are nociceptive small-fiber endings and axonal localization of epidermal PGP9.5 immunolabeling has been verified ultrastructurally [42;48]. A single skilled morphometrist blinded to group allocation measured ENF density. Our laboratory reports ENF densities per $\mathrm{mm}^{2}$ skin surface area to control for varying skin-section thickness between laboratories. Skin biopsy corroboration of SFPN required meeting the standard clinical diagnostic criteria for SFPN diagnosis, namely ENF density $<5^{\text {th }}$ centile of predicted laboratory norm [28]. Our laboratory's sex, age, and race-specific norms come from multivariate analysis of 240 screened normal volunteers' biopsies [25].

AFT was also performed using the standard clinical diagnostic methods, equipment (WR Medical Electronics, Stillwater, MN) and interpretations recommended for SFPN diagnosis $[1 ; 8]$. Subjects were directed to not wear compressive clothing, and not to smoke, eat, or consume alcohol or caffeine for 4 hours preceding testing. Their medications were reviewed and potentially interfering medications were held for 24-48 hours before testing (all medications with anticholinergic effects including pain medications, antidepressants, antihistamines, cough and cold remedies; cardiovascular modulators including adrenergics, diuretics, anti-hypotensive agents, and attention-deficit medications) [9;33]. We measured heart-rate variability to deep breathing (6/minute while supine) and Valsalva maneuver, hemodynamic responses to $80^{\circ}$ head-up tilt for 10 minutes, and acetylcholine-evoked sweat production. We applied the sole validated quantitative scoring system (Composite Autonomic Scoring Scale) [30], and later modifications [33;35;36], incorporating equipment-specific reference ranges. Corroboration of SFPN by AFT required at least $2 / 4$ abnormal AFT subtest results. Standard sex and age-adjusted definitions of abnormality were used: Abnormal heart rate response to deep breathing comprised $<2.5^{\text {th }}$ centile of predicted norm, and abnormal response to the Valsalva maneuver comprised no change in phase II and/or Valsalva ratio $<2.5^{\text {th }}$ centile [33]. Abnormal tilt-table response comprised change in heart rate $\geq 30$ and/or reductions in systolic blood-pressure $\geq 20$ or reductions in diastolic blood-pressure $\geq 10$ [13;33]. Abnormal sweat production comprised at least 2 sites $<50 \%$ of $5^{\text {th }}$ centile of norm for sex and age [33]. Since we used a Q-Sweat machine but published diagnostic norms use QSART data, we converted our measurements to QSART units [32].

\subsection{Outcome variables and data analysis}

There are no consensus diagnostic clinical or research criteria for SFPN in adults or children [7], so we followed standard clinical practice in accepting any one or more objective-test result consistent with SFPN as confirming the diagnosis in a person who has sought medical help for otherwise-unexplained symptoms consistent with SFPN [8;28]. Summary statistics comprised group means \pm standard errors. Proportions of abnormal results were compared between groups by Chi-square analysis.

\section{Results}

\subsection{Validation of study groups}

Table 1 demonstrates that the samples of fibromyalgia and control subjects were demographically similar and that the FMS subjects were similar in age, sex, and race to larger cohorts of FMS patients including those used to define the syndrome [39;51]. The mean age at onset of FMS in the current cohort was $28.8 \pm 3.0$ years, and illness duration averaged $19.1 \pm 2.7$ years. Scores on the Beck Depression Inventory identified control subjects as not depressed and FMS subjects as mildly depressed on average, consistent with prior FMS cohorts [3;23]. The physical (PCS) and mental component scores (MCS) of the SF-36 identified control subjects as at or near the population mean of 50, whereas FMS 
subjects had significantly lower scores consistent with illness (both $\mathrm{p}<0.001$, Table 1 ). The mean MCS score among FMS subjects (40.2) was very similar to MCS scores reported from larger FMS cohorts $(38.6,43.1)$, but their PCS scores (35.6) were less abnormal $(28.0,29.6)$, suggesting that the current sample may have had slightly less physical disability than historical FMS cohorts (as reviewed in [19]).

\subsection{Symptoms and signs consistent with SFPN}

The Michigan Neuropathy Screening Instrument (MNSI) has a range of possible scores between $0-15$ with abnormal previously defined as > 2 [34]. MNSI scores from 28 control subjects were on average in the normal range $(1.3 \pm 0.3)$, whereas scores from the 23 FMS subjects were on average abnormal and consistent with polyneuropathy $(5.8 \pm 0.6, P \leq$ 0.001, Table 1). Results of the Utah Early Neuropathy Scale (UENS) standardized neurological examination were available from 27 FMS and 26 control subjects. UENS scores range between $0-42$, with the ideal score $=0$. There is no established cut-off between normal and abnormal. UENS scores from FMS subjects were significantly higher than scores from control subjects ( $3.1 \pm 0.7$ vs. $0.5 \pm 0.2, P \leq 0.001$, Table 1 ), providing evidence that the FMS group but not the control group had examination findings consistent with SFPN. Figure 3 depicts the different categories of results on the MNSI and UENS. The lack of allodynia among FMS patients on both the UENS and the Sensory category of the MNSI was of interest.

\subsection{Objective tests corroborative of SFPN}

Overall $50 \%$ of fibromyalgia subjects vs. $17 \%$ of controls had one or more objective test result consistent with SFPN ( $P \leq 0.001$; Table 1). Skin-biopsy results (Figure 2 ) drove this difference, with $41 \%$ of biopsies from FMS patients vs. $3 \%$ of biopsies from control subjects having ENF densities $<5^{\text {th }}$ centile of predicted laboratory norm $(P \leq 0.001$; Table 1$)$. One control subject met skin-biopsy criteria for SFPN, without corresponding symptoms or signs $\left(\mathrm{ENF}=<1^{\text {st }}\right.$ centile, MNSI score $\leq 2$, UENS score $\left.=0\right)$. This was tentatively attributed to a concurrent diagnosis of multiple endocrine neoplasia-2 including thyroid cancer, which has been associated with axonopathy [5]. In contrast, AFT results were overall similar between fibromyalgia patients and control subjects $(P=0.27$; Table 1$)$. One subject from each group had abnormally reduced heart-rate changes during deep breathing $(P=0.46), 7$ FMS subjects vs. 3 controls had abnormal responses to Valsalva $(P=0.0006), 9$ subjects in each group had abnormal responses to tilt $(P=0.50)$, and 4 FMS subjects vs. 0 controls had low sweat production at more than one site ( $P$ undefined).

\subsection{Comparing results from fibromyalgia subjects with vs. without skin biopsies corroborative of SFPN}

Given the highly significant differences in skin biopsy results and lack of differences in AFT results between FMS and control subjects, we performed a secondary analysis to compare the other test results between FMS subjects who did or did not meet skin-biopsy criteria for SFPN. Table 2 demonstrates that FMS subjects with SFPN-diagnostic skin biopsies were similar in sex and age (70\% female, mean age $46.4 \pm 2.8$ years) to FMS subjects with nondiagnostic skin biopsies (77\% female, mean age $46.7 \pm 3.7$ years). However, all FMS/SFPN subjects were Caucasian compared to only $57 \%$ of non-SFPN/FMS subjects $(P=0.003)$. The mean ENF centile value among FMS/SFPN subjects was $3.8 \pm 1.9$, whereas it was at the population mean $(48.2 \pm 7.2)$ among non-SFPN/FMS subjects $(P<0.001)$. Additionally, $39 \%$ of SFPN/FMS subjects had abnormal AFT results whereas $0 \%$ of non-SFPN/FMS subjects did. On the MNSI, UENS, BDI, and SF-36, both groups had largely similar results (Table 2), all consistent with FMS. 


\subsection{Underlying causes of SFPN among fibromyalgia subjects}

Testing for known causes of SFPN causality among FMS/SFPN subjects had not been planned, but this was requested by so many subjects with skin biopsies diagnostic for SFPN that we offered the recommended blood tests to all of them [9]. All 13 FMS/SFPN subjects had hemoglobin $\mathrm{A}_{1 \mathrm{C}}<6.0 \mathrm{mg} / \mathrm{dl}$. Among two-hour glucose-tolerance tests (75 g load) 8/11 were normal using current American Diabetes Association criteria. Two subjects had barely impaired fasting glucose $(100 \mathrm{mg} / \mathrm{dL}, 102 \mathrm{mg} / \mathrm{dL})$ one accompanied by marginal glucose intolerance $(2 \mathrm{hr}=140 \mathrm{mg} / \mathrm{dl})$. The two FMS/SFPN subjects who did not undergo glucosetolerance tests had normal random glucoses $(90,100 \mathrm{mg} / \mathrm{dl})$. In contrast, $2 / 11$ patients tested positive for hepatitis $\mathrm{C}$ - one a known case, the other a new diagnosis. All 13 subjects had noncontributory serum chemistries, blood counts, thyroid function, folate levels, triglycerides, C-reactive protein, angiotensin converting enzyme, tests for Lyme disease, lupus, Sjögren's disease, and celiac (IgA tissue-transglutaminase autoantibodies). None among 12 tested by immunofixation had monoclonal gammopathies. All 11 tested had vitamin B12 levels within the reference range.

The most common blood-test abnormalities FMS/SFPN subjects were those specific serologic markers of dysimmunity that have been associated with juvenile-onset SFPN [37]. Specifically, $5 / 13$ subjects had elevated erythrocyte sedimentation rates ( $\geq 25 \mathrm{~mm} / \mathrm{hr}$ ), $4 / 13$ had antinuclear antibodies at titers greater than or equal to $1: 160$, and 3/13 had low complement $\mathrm{C} 4$, with $2 / 3$ also having low complement $\mathrm{C} 3$ [37]. Overall, $62 \%$ of FMS/SFPN subjects had one or more among these markers of dysimmune function.

\subsection{Adverse Events}

Skin biopsy caused no adverse events, but one subject suffered two small second-degree burns during sweat testing. Detailed investigation implicated faulty grounding electrodes and there were no further events after a different ground pad was substituted.

\section{Discussion}

The current results demonstrate that half among a small community-based sample of patients with fibromyalgia syndrome (FMS) also had objective test results universally accepted as corroborative of a diagnosis of small-fiber polyneuropathy (SFPN), a biologically plausible cause of their FMS symptoms. The difference between FMS and SFPN labels is not merely semantic - SFPN is an established disease with considerable information established about pathogenesis whereas FMS is an aggregate of symptoms without prior evidence of a biological basis. Unlike FMS, SFPN can be objectively tested for (as here) and some causes of SFPN can be definitively treated, so advancing a patient's "diagnosis" beyond FMS to SFPN suggests potential etiologies, some of which can be tested for and treated. Skin biopsy (Figure 2) corroborated SFPN in 41\% of FMS subjects vs. 3\% of normal controls, whereas both groups had similar results of autonomic function testing, implicating a primarily somatic and distal small-fiber polyneuropathy affecting pain neurons. This is consistent with the centrality of chronic widespread pain (CWP) rather than dysautonomic symptoms as the defining feature of the FMS phenotype.

This prospective study is limited by its small size. It was designed to detect large but not small effects so AFT should be re-evaluated in a larger cohort, particularly sweat production and responses to Valsalva for which FMS patients differed from controls. The observation that FMS subjects with SFPN were more likely to be Caucasians than those without SFPN $(P=0.003)$ also needs re-evaluation in a larger study. However small, our FMS group was demographically representative of larger FMS cohorts, e.g., the 258 patients from whom the current ACR diagnostic criteria were derived ( $92 \%$ female, mean age 55y, $87 \%$ nonHispanic white [51]) and a community-based cohort of 10,129 FMS patients (63\% female, 
mean age 46y, races not reported [39]). Another limitation is the uncertain sensitivity and specificity of skin biopsy and autonomic function testing. Since there is no absolute or "gold standard" diagnostic test for SFPN against which to measure them, their sensitivity and specificity cannot be defined except as relative to each other. Even these best-available tests are imperfect; indeed $13 \%$ of control subjects had abnormal AFT results. Tilt-table abnormalities were most common, consistent with the prevalence of orthostatic hypotension in the general population [31]. In contrast, skin biopsy, which measures late-stage axonal degeneration, had $97 \%$ specificity among control subjects in the current study. Another limitation is that we did not test subjects for other types of neuropathy such as demyelinating neuropathies, motor or large-fiber sensory axonopathies, focal lesions, auditory neuropathies. There is increasing recognition that different types of neurons are affected to varying extents in most polyneuropathies, regardless of how they are classified, particularly in severe or long-standing cases, and evidence of large-fiber motor or sensory polyneuropathy does not invalidate the presence of small-fiber polyneuropathy.

Study strengths included recruitment from the community to minimize referral or investigator bias, and use of rigorous inclusion criteria for FMS. We required both a preexisting, independent FMS diagnosis plus satisfying ACR research criteria, since these can be discordant [24]. The similarly rigorous and consensus-based evaluation for SFPN was an additional strength. Of note, both physiological (AFT) and anatomical tests for small-fiber polyneuropathy were applied. We also included assessments of depression and disability, which helped validate the representativeness of the study samples.

Another strength is that we acquired data regarding potential underlying causes of SFPN among subjects with SFPN-diagnostic skin biopsies. We did not study controls since the definition of "abnormal" for clinical blood tests is based on extensive testing in normal as well as illness samples. Although diabetes is the most common cause of SFPN in developed countries, we found no evidence of causal contributions from diabetes or hyperglycemia. In contrast, 2/11 patients tested positive for hepatitis $\mathrm{C}$ including one previously undiagnosed patient who was referred for treatment of hepatitis $\mathrm{C}$ since most cases are now curable. Five patients had serologic markers of autoimmunity that have been associated with juvenileonset SFPN, a newly characterized type of SFPN that is associated with organ-specific, complement-consuming, humoral dysimmunity and some favorable responses to immunomodulatory treatments [37;38]. Although most of the FMS subjects were middleaged at the time of study, they reported onset of their FMS in youth, meaning that some could have had longstanding cases of juvenile-onset SFPN.

Three FM/SFPN subjects turned out to be related - a mother and two daughters. Given these study results, other members of their family who also suffered from juvenile-onset FMS sought evaluation for SFPN leading to revised diagnoses of objectively confirmed SFPN in at least 6 family members in 4 generations. A genetic cause was presumed and genetic evaluation recommended. The well-known hereditary sensory and autonomic neuropathies (HSAN) were considered unlikely due to the absence of trophic signs (e.g., painless ulcers). SFPN has more recently been linked to gain-of-function mutations in the SCN9A gene encoding the Nav1.7 sodium-channel isoform that is preferentially expressed in small-fiber nociceptive neurons, but commercial tests are not yet available [10]. FMS has also been recently associated with a specific $S C N 9 A$ polymorphism [46], providing potential additional evidence of convergence between FMS and SFPN. Although there is no cure for the genetic forms of SFPN yet, a trial of L-serine is underway for HSAN-1 [14], and identifying specific mutations can guide patients towards targeted therapies not usually considered for FMS patients, such as sodium-channel blockers. 
In conclusion, this study provides objective evidence that almost half of a small sample of patients labeled with fibromyalgia syndrome have objective evidence of a neurologic cause of their chronic widespread pain and other fibromyalgia symptoms, namely small-fiber polyneuropathy, a distinct peripheral-nerve disease. Blood tests in the small group of SFPNdiagnosed patients suggested that known causes of SFPN in the young (dysimmune, genetic, and infectious) were more common than causes of SFPN in maturity (e.g., diabetes, cancer, vitamin deficiencies or toxins), and they identified some treatable or curable etiologies such as hepatitis C. Patients currently carrying the FMS label may wish to discuss with their physicians whether testing for small-fiber polyneuropathy and its underlying causes might help them.

\section{Acknowledgments}

Supported in part by the Public Health Service (NINDS K24NS059892, UIL RR025758), the Department of Defense (GW093049), and a charitable donation from Ms. Jane Cheever Powell. Presented in abstract form to the 2012 meeting of the American Neurological Association. We thank the subjects for their participation, and Kate O’Neil and Siena Napoleon for assistance.

\section{References}

1. Assessment: Clinical autonomic testing report of the Therapeutics and Technology Assessment Subcommittee of the American Academy of Neurology. Neurology. 1996; 46:873-880. [PubMed: 8618715]

2. Aalto AM, Elovainio M, Kivimaki M, Uutela A, Pirkola S. The Beck Depression Inventory and General Health Questionnaire as measures of depression in the general population: a validation study using the Composite International Diagnostic Interview as the gold standard. Psychiatry Res. 2012; 197:163-171. [PubMed: 22365275]

3. Akkaya N, Akkaya S, Atalay NS, Balci CS, Sahin F. Relationship between the body image and level of pain, functional status, severity of depression, and quality of life in patients with fibromyalgia syndrome. Clin Rheumatol. 2012; 31:983-988. [PubMed: 22395855]

4. Amato AA, Oaklander AL. Case records of the Massachusetts General Hospital. Case 16-2004. A 76-year-old woman with pain and numbness in the legs and feet. N Engl J Med. 2004; 350:21812189. [PubMed: 15152064]

5. Califano D, D'Alessio A, Colucci-D'Amato GL, De Vita G, Monaco C, Santelli G, Di Fiore PP, Vecchio G, Fusco A, Santoro M, de Franciscis V. A potential pathogenetic mechanism for multiple endocrine neoplasia type 2 syndromes involves ret-induced impairment of terminal differentiation of neuroepithelial cells. Proceedings of the National Academy of Sciences. 1996; 93:7933-7937.

6. Caro XJ, Winter EF, Dumas AJ. A subset of fibromyalgia patients have findings suggestive of chronic inflammatory demyelinating polyneuropathy and appear to respond to IVIg. Rheumatology (Oxford). 2008; 47:208-211. [PubMed: 18208823]

7. Devigili G, Tugnoli V, Penza P, Camozzi F, Lombardi R, Melli G, Broglio L, Granieri E, Lauria G. The diagnostic criteria for small fibre neuropathy: from symptoms to neuropathology. Brain. 2008; 131:1912-1925. [PubMed: 18524793]

8. England JD, Gronseth GS, Franklin G, Carter GT, Kinsella LJ, Cohen JA, Asbury AK, Szigeti K, Lupski JR, Latov N, Lewis RA, Low PA, Fisher MA, Herrmann DN, Howard JF Jr, Lauria G, Miller RG, Polydefkis M, Sumner AJ. Practice Parameter: Evaluation of distal symmetric polyneuropathy: role of autonomic testing, nerve biopsy, and skin biopsy (an evidence-based review). Report of the American Academy of Neurology, American Association of Neuromuscular and Electrodiagnostic Medicine, and American Academy of Physical Medicine and Rehabilitation Neurology. 2009; 72:177-184.

9. England JD, Gronseth GS, Franklin G, Carter GT, Kinsella LJ, Cohen JA, Asbury AK, Szigeti K, Lupski JR, Latov N, Lewis RA, Low PA, Fisher MA, Herrmann DN, Howard JF Jr, Lauria G, Miller RG, Polydefkis M, Sumner AJ. Practice Parameter: Evaluation of distal symmetric polyneuropathy: role of laboratory and genetic testing (an evidence-based review). Report of the AAN, AANEM, and AAPMR Neurology. 2009; 72:185-192. 
10. Faber CG, Hoeijmakers JGJ, Ahn HS, Cheng X, Han C, Choi JS, Estacion M, Lauria G, Vanhoutte EK, Gerrits MM, Dib-Hajj S, Drenth JPH, Waxman SG, Merkies ISJ. Gain of function NaV1. 7 mutations in idiopathic small fiber neuropathy. Ann Neurol. 2012; 71:26-39. [PubMed: 21698661]

11. Feldman EL, Stevens MJ, Thomas PK, Brown MB, Canal N, Greene DA. A practical two-step quantitative clinical and electrophysiological assessment for the diagnosis and staging of diabetic neuropathy. Diabetes Care. 1994; 17:1281-1289. [PubMed: 7821168]

12. Freeman R, Chase KP, Risk MR. Quantitative sensory testing cannot differentiate simulated sensory loss from sensory neuropathy. Neurology. 2003; 60:465-470. [PubMed: 12578928]

13. Freeman R, Wieling W, Axelrod FB, Benditt DG, Benarroch E, Biaggioni I, Cheshire WP, Chelimsky T, Cortelli P, Gibbons CH, Goldstein DS, Hainsworth R, Hilz MJ, Jacob G, Kaufmann H, Jordan J, Lipsitz LA, Levine BD, Low PA, Mathias C, Raj SR, Robertson D, Sandroni P, Schatz I, Schondorf R, Stewart JM, van Dijk JG. Consensus statement on the definition of orthostatic hypotension, neurally mediated syncope and the postural tachycardia syndrome. Clin Auton Res. 2011; 21:69-72. [PubMed: 21431947]

14. Garofalo K, Penno A, Schmidt BP, Lee HJ, Frosch MP, von EA, Brown RH, Hornemann T, Eichler FS. Oral 1-serine supplementation reduces production of neurotoxic deoxysphingolipids in mice and humans with hereditary sensory autonomic neuropathy type 1. J Clin Invest. 2011; 121:4735-4745. [PubMed: 22045570]

15. Gibbons CH, Wang N, Freeman R. Capsaicin induces degeneration of cutaneous autonomic nerve fibers. Ann Neurol. 2010; 68:888-898. [PubMed: 21061393]

16. Gorson KC, Herrmann DN, Thiagarajan R, Brannagan T, Chin RL, Kinsella LJ, Ropper AH. Nonlength dependent small fiber neuropathy small neuropathy/ganglionopathy. J Neurol Neurosurg Psychiatry. 2007; 79:163-169. [PubMed: 17911181]

17. Gracely RH, Petzke F, Wolf JM, Clauw DJ. Functional magnetic resonance imaging evidence of augmented pain processing in fibromyalgia. Arthritis \& Rheumatism. 2002; 46:1333-1343. [PubMed: 12115241]

18. Harris PA, Taylor R, Thielke R, Payne J, Gonzalez N, Conde JG. Research electronic data capture (REDCap)--a metadata-driven methodology and workflow process for providing translational research informatics support. J Biomed Inform. 2009; 42:377-381. [PubMed: 18929686]

19. Hoffman DL, Dukes EM. The health status burden of people with fibromyalgia: a review of studies that assessed health status with the SF-36 or the SF-12. Int J Clin Pract. 2008; 62:115-126. [PubMed: 18039330]

20. Holzer P. Efferent-like roles of afferent neurons in the gut: Blood flow regulation and tissue protection. Auton Neurosci. 2006; 125:70-75. [PubMed: 16542883]

21. Hsu MC, Harris RE, Sundgren PC, Welsh RC, Fernandes CR, Clauw DJ, Williams DA. No consistent difference in gray matter volume between individuals with fibromyalgia and agematched healthy subjects when controlling for affective disorder. Pain. 2009; 143:262-267. [PubMed: 19375224]

22. Jensen KB, Kosek E, Petzke F, Carville S, Fransson P, Marcus H, Williams SCR, Choy E, Giesecke T, Mainguy Y, Gracely R, Ingvar M. Evidence of dysfunctional pain inhibition in fibromyalgia reflected in rACC during provoked pain. Pain. 2009; 144:95-100. [PubMed: 19410366]

23. Jensen KB, Petzke F, Carville S, Fransson P, Marcus H, Williams SC, Choy E, Mainguy Y, Gracely R, Ingvar M, Kosek E. Anxiety and depressive symptoms in fibromyalgia are related to poor perception of health but not to pain sensitivity or cerebral processing of pain. Arthritis Rheum. 2010; 62:3488-3495. [PubMed: 20617526]

24. Katz RS, Wolfe F, Michaud K. Fibromyalgia diagnosis: a comparison of clinical, survey, and American College of Rheumatology criteria. Arthritis Rheum. 2006; 54:169-176. [PubMed: 16385512]

25. Klein MM, Downs H, Oaklander AL. Normal innervation in distal-leg skin biopsies: evidence of superabundance in youth, subsequent axonal pruning, plus new diagnostic recommendations. Annals of Neurology. 2010; 68:S68. 
26. Koroschetz J, Rehm SE, Gockel U, Brosz M, Freynhagen R, Tolle TR, Baron R. Fibromyalgia and neuropathic pain--differences and similarities. A comparison of 3057 patients with diabetic painful neuropathy and fibromyalgia. BMC Neurol. 2011; 11:55. [PubMed: 21612589]

27. Lauria G, Cornblath DR, Johansson O, McArthur JC, Mellgren SI, Nolano M, Rosenberg N, Sommer C. EFNS guidelines on the use of skin biopsy in the diagnosis of peripheral neuropathy. Eur J Neurol. 2005; 12:747-758. [PubMed: 16190912]

28. Lauria G, Hsieh ST, Johansson O, Kennedy WR, Leger JM, Mellgren SI, Nolano M, Merkies IS, Polydefkis M, Smith AG, Sommer C, Valls-Sole J. European Federation of Neurological Societies/Peripheral Nerve Society Guideline on the use of skin biopsy in the diagnosis of small fiber neuropathy. Report of a joint task force of the European Federation of Neurological Societies and the Peripheral Nerve Society. Eur J Neurol. 2010; 17:903-909. [PubMed: 20642627]

29. Lindell L, Bergman S, Petersson IF, Jacobsson LT, Herrstrom P. Prevalence of fibromyalgia and chronic widespread pain. Scand J Prim Health Care. 2000; 18:149-153. [PubMed: 11097099]

30. Low PA. Composite autonomic scoring scale for laboratory quantification of generalized autonomic failure. Mayo Clin Proc. 1993; 68:748-752. [PubMed: 8392653]

31. Low PA. Prevalence of orthostatic hypotension. Clin Auton Res. 2008; 18 (Suppl 1):8-13. [PubMed: 18368301]

32. Low PA, Denq JC, Opfer-Gehrking TL, Dyck PJ, O'Brien PC, Slezak JM. Effect of age and gender on sudomotor and cardiovagal function and blood pressure response to tilt in normal subjects. Muscle Nerve. 1997; 20:1561-1568. [PubMed: 9390669]

33. Low, PA.; Sletten, DM. Laboratory evaluation of autonomic failure. In: Low, PA.; Benarroch, EE., editors. Clinical Autonomic Disorders. Baltimore: Lippincott Williams \& Wilkins; 2008. p. 130-163.

34. Moghtaderi A, Bakhshipour A, Rashidi H. Validation of Michigan neuropathy screening instrument for diabetic peripheral neuropathy. Clinical Neurology and Neurosurgery. 2006; 108:477-481. [PubMed: 16150538]

35. Novak P. Assessment of sympathetic index from the Valsalva maneuver. Neurology. 2011; 76:2010-2016. [PubMed: 21646629]

36. Novak P. Quantitative autonomic testing. J Vis Exp. 2011:1-20.

37. Oaklander AL, Klein MM. Evidence of small-fiber polyneuropathy in unexplained, juvenile- onset, widespread pain syndromes. Pediatrics. 2013; 131:e1091-e1100. [PubMed: 23478869]

38. Paticoff J, Valovska A, Nedeljkovic SS, Oaklander AL. Defining a treatable cause of erythromelalgia: acute adolescent autoimmune small-fiber axonopathy. Anesth Analg. 2007; 104:438-441. [PubMed: 17242106]

39. Reed C, Birnbaum HG, Ivanova JI, Schiller M, Waldman T, Mullen RE, Swindle R. Real-world role of tricyclic antidepressants in the treatment of fibromyalgia. Pain Pract. 2012; 12:533-540. [PubMed: 22226400]

40. Ruscheweyh R, Deppe M, Lohmann H, Stehling C, Flöel A, Ringelstein EB, Knecht S. Pain is associated with regional grey matter reduction in the general population. Pain. 2011; 152:904-911. [PubMed: 21296501]

41. Shtein, R.; Hussain, M.; Hamid, M.; Raval, N.; Williams, DA.; Clauw, DJ. In vivo corneal confocal microscopy and clinical correlations in fibromyalgia (FM). Meeting of the International Association for the Study of Pain; 2012.

42. Simone DA, Nolano M, Johnson T, Wendelschafer-Crabb G, Kennedy WR. Intradermal injection of capsaicin in humans produces degeneration and subsequent reinnervation of epidermal nerve fibers: correlation with sensory function. J Neurosci. 1998; 18:8947-8959. [PubMed: 9787000]

43. Singleton JR, Bixby B, Russell JW, Feldman EL, Peltier A, Goldstein J, Howard J, Smith AG. The Utah Early Neuropathy Scale: a sensitive clinical scale for early sensory predominant neuropathy. J Peripher Nerv Syst. 2008; 13:218-227. [PubMed: 18844788]

44. Solà, R.; Collado, A.; Antonelli, F.; Quiles, C.; Serra, J. Is fibromyalgia a special type of small fiber neuropathy? A microneurography study. Meeting of the International Association for the Study of Pain; 2012. 
45. Üçeyler, N.; Kahn, A-K.; Zeller, D.; Kewenig, S.; Kittel-Schneider, S.; Reiners, K.; Sommer, C. Functional and morphological impairment of small nerve fibers in fibromyalgia syndrome. Meeting of the International Association for the Study of Pain; 2012.

46. Vargas-Alarcon G, Alvarez-Leon E, Fragoso JM, Vargas A, Martinez A, Vallejo M, MartinezLavin M. A SCN9A gene-encoded dorsal root ganglia sodium channel polymorphism associated with severe fibromyalgia. BMC Musculoskelet Disord. 2012; 13:23-28. [PubMed: 22348792]

47. Vincent K, Warnaby C, Stagg CJ, Moore J, Kennedy S, Tracey I. Dysmenorrhoea is associated with central changes in otherwise healthy women. Pain. 2011; 152:1966-1975. [PubMed: 21524851]

48. Wang L, Hilliges M, Jernberg T, Wiegleb-Edstrom D, Johansson O. Protein gene product 9. 5immunoreactive nerve fibres and cells in human skin. Cell Tissue Res. 1990; 261:25-33. [PubMed: 2143435]

49. White KP, Speechley M, Harth M, Ostbye T. The London Fibromyalgia Epidemiology Study: direct health care costs of fibromyalgia syndrome in London, Canada. J Rheumatol. 1999; 26:885889. [PubMed: 10229411]

50. White KP, Speechley M, Harth M, Ostbye T. The London Fibromyalgia Epidemiology Study: the prevalence of fibromyalgia syndrome in London, Ontario. J Rheumatol. 1999; 26:1570-1576. [PubMed: 10405947]

51. Wolfe F, Clauw DJ, Fitzcharles MA, Goldenberg DL, Katz RS, Mease P, Russell AS, Russell IJ, Winfield JB, Yunus MB. The American College of Rheumatology preliminary diagnostic criteria for fibromyalgia and measurement of symptom severity. Arthritis Care Res (Hoboken). 2010; 62:600-610. [PubMed: 20461783]

52. Wolfe F, Smythe HA, Yunus MB, Bennett RM, Bombardier C, Goldenberg DL, Tugwell P, Campbell SM, Abeles M, Clark P. The American College of Rheumatology 1990 criteria for the classification of fibromyalgia. Report of the multicenter criteria committee. Arthritis Rheum. 1990; 33:160-172. [PubMed: 2306288] 


\section{\begin{tabular}{l|l} 
Fibromyalgia Subjects & Control Subjects
\end{tabular}}



Figure 1.

Enrollment and Outcomes 



Figure 2.

Immunohistochemical visualization of sensory nerve endings in distal-leg skin biopsy by anti-PGP9.5-immunoreactivity. Arrows depict labeled axons. Panel A: Biopsy from 44-year old Caucasian, female, control subject with normal density of epidermal innervation (337 neurites $/ \mathrm{mm}^{2}$ skin surface area; at the $76^{\text {th }}$ centile of predicted value). Panel B: Biopsy from 47-year old Caucasian, female, fibromyalgia subject with reduced density of epidermal innervation diagnostic for small-fiber polyneuropathy (135 neurites $/ \mathrm{mm}^{2}$ skin surface area; at the $3^{\text {rd }}$ centile of predicted value). Bars represent 50 micrometers. 

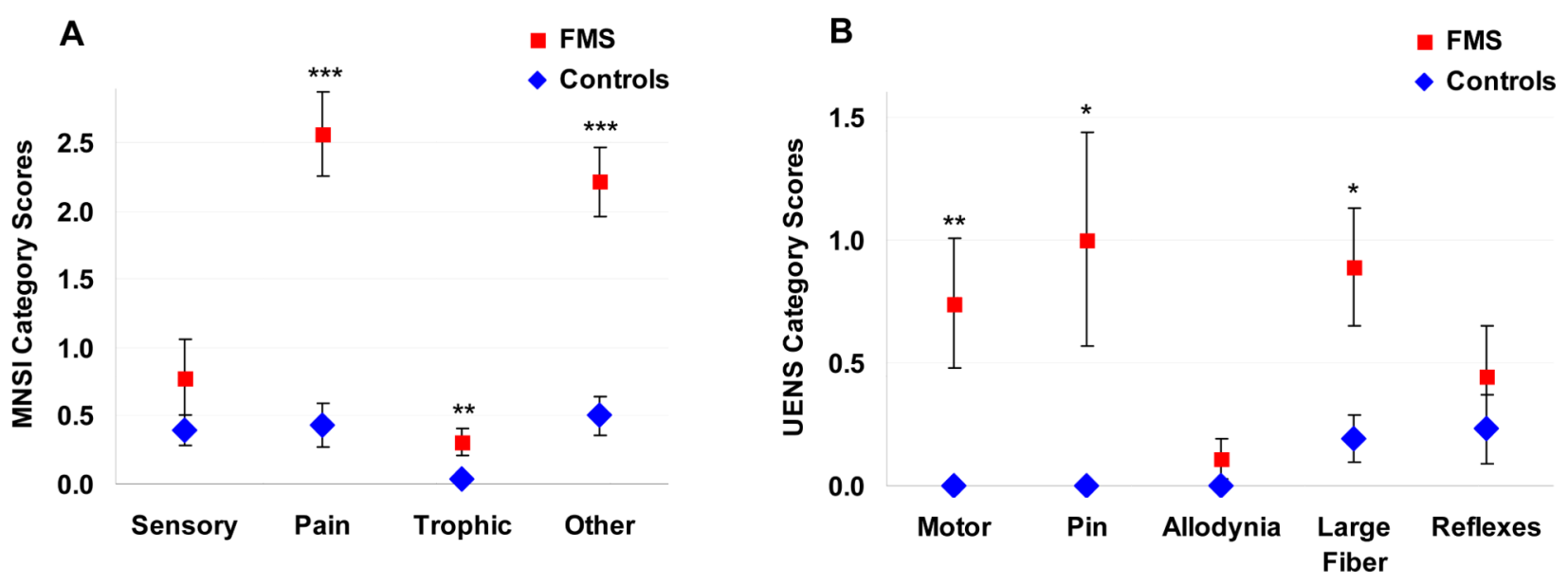

Figure 3.

Evidence of SFPN from neuropathy symptom scales. (A) Comparison of Michigan Neuropathy Screening Instrument scores for FMS and control subjects by questionnaire category. Sensory comprised MNSI questions 1, 7, 13; Pain comprised questions 2, 3, 5, 6, 12; Trophic comprised questions 8, 14, 15; Other comprised questions 4, 9, 10, 11. (B) Comparison of Utah Early Neuropathy Scale scores for FMS and control subjects by examination category: Motor (great toe extension); Pin (absent and reduced sensation); Allodynia (in toes and foot); Large Fiber Sensation (vibration and great toe position); and Reflexes (deep tendon at the ankle). ${ }^{*} P<0.05, * * P<0.01, * * * P<0.001$. 
Table 1

Summary statistics for all study participants

\begin{tabular}{|c|c|c|c|}
\hline Characteristic & Fibromyalgia Subjects, n=27 & Control Subjects, $n=30$ & $P$ \\
\hline \multicolumn{4}{|c|}{ DEMOGRAPHIC VARIABLES } \\
\hline Age, mean yr (+/- SEM) & $46.5(2.3)$ & $44.8(1.9)$ & 0.576 \\
\hline Age range, yr & $26-68$ & $25-65$ & -- \\
\hline Female gender, No. [\%] & $20[74.1 \%]$ & $24[80.0 \%]$ & 0.460 \\
\hline White race, No. [\%] & $21[77.8 \%]$ & $22[73.3 \%]$ & 0.361 \\
\hline Duration of fibromyalgia symptoms, mean yr (+/- SEM) & $19.1(2.7)$ & & \\
\hline \multicolumn{4}{|c|}{ OBJECTIVE TEST RESULTS } \\
\hline ENF density $<5 \%$, No. $[\%]^{a}$ & $11[40.7 \%]$ & $1[3.4 \%]$ & $1.14 \times 10^{-24}$ \\
\hline Abnormal AFT, No. $[\%]^{b}$ & $5[19.2 \%]$ & $4[13.3 \%]$ & 0.271 \\
\hline One or more of the above, No. $[\%]^{c}$ & $13[50.0 \%]$ & $5[17.2 \%]$ & $2.40 \times 10^{-5}$ \\
\hline \multicolumn{4}{|c|}{ SIGNS AND SYMPTOMS (range $=$ healthy $\rightarrow$ ill) } \\
\hline MNSI, mean \pm SEM (range 0-15; abnormal > 2) & $8 \pm 0.6$ & $1.3 \pm 0.3$ & $2.11 \times 10^{-9}$ \\
\hline UENS \pm SEM (range $0-42 ;$ ideal $=0$ ) & $1 \pm 0.7$ & $0.5 \pm 0.2$ & $6.21 \times 10^{-4}$ \\
\hline BDI, mean \pm SEM $($ range $0-63$; ideal $=0$ ) & $4.4 \pm 1.8$ & $3.3 \pm 0.8$ & $4.35 \times 10^{-7}$ \\
\hline SF-36 PCS \pm SEM (range $100-0, \mu=50, S D=10)$ & $5.6 \pm 2.1$ & $52.5 \pm 1.4$ & $8.07 \times 10^{-9}$ \\
\hline SF-36 MCS \pm SEM (range $100-0, \mu=50, S D=10)$ & $0.2 \pm 2.4$ & $54.7 \pm 1.2$ & $1.26 \times 10^{-6}$ \\
\hline
\end{tabular}

${ }^{a}$ One control subject declined biopsy

${ }^{b}$ One fibromyalgia subject withdrew from sweat test



$\mathrm{AFT}=$ autonomic function test, $\mathrm{BDI}=\mathrm{Beck}$ Depression Inventory, $\mathrm{ENF}=$ epidermal nerve fiber, $\mathrm{MCS}=$ mental component summary, $\mathrm{MNSI}=$ Michigan Neuropathy Screening Instrument, PCS = physical component summary, SEM = standard error of the mean, SF-36 = Medical Outcomes Study Short Form Health Survey, SFPN = small-fiber polyneuropathy, UENS = Utah Early Neuropathy Scale 


\section{Table 2}

Summary statistics comparing FMS subjects with or without objective evidence of SFPN

\begin{tabular}{|c|c|c|c|}
\hline Characteristic & $\begin{array}{l}\text { FMS Subjects with objective } \\
\text { evidence of SFPN, } n=13\end{array}$ & $\begin{array}{l}\text { FMS Subjects without objective } \\
\text { evidence of SFPN, } n=14\end{array}$ & $\boldsymbol{P}$ \\
\hline \multicolumn{4}{|c|}{ DEMOGRAPHIC VARIABLES } \\
\hline Age, mean yr (+/- SEM) & $46.4(2.8)$ & $46.7(3.7)$ & 0.951 \\
\hline Age range, yr & $26-63$ & $28-68$ & -- \\
\hline Female gender, No. [\%] & $9[69.2 \%]$ & $11[78.6 \%]^{a}$ & 0.404 \\
\hline White race, No. [\%] & $13[100.0 \%]$ & $8[57.1 \%]$ & 0.003 \\
\hline \multicolumn{4}{|c|}{ OUTCOMES (range = normal $\rightarrow$ abnormal) } \\
\hline ENF, mean centile $(+/-$ SEM) & $3.8(1.9)$ & $48.2(7.2)$ & 0.00001 \\
\hline ENF density $<5 \%$, No. $[\%]^{b}$ & $11[84.6 \%]$ & $0[0.0 \%]$ & \\
\hline Abnormal AFT, No. [\%] & $5[38.5 \%]$ & $0[0.0 \%]$ & \\
\hline MNSI, mean \pm SEM (range $0-15 ;$ abnormal > 2) & $6.6 \pm 0.6$ & $4.7 \pm 0.9$ & 0.085 \\
\hline UENS \pm SEM (range $0-42 ;$ ideal $=0$ ) & $3.8 \pm 1.2$ & $2.5 \pm 0.8$ & 0.340 \\
\hline BDI, mean \pm SEM (range 0-63; ideal = 0) & $18.5 \pm 2.5$ & $10.7 \pm 2.2$ & 0.028 \\
\hline SF-36 PCS \pm SEM (range $100-0, \mu=50, S D=10)$ & $35.5 \pm 3.6$ & $35.7 \pm 2.3$ & 0.963 \\
\hline SF-36 MCS \pm SEM (range $100-0, \mu=50, S D=10)$ & $35.1 \pm 2.8$ & $44.9 \pm 3.4$ & 0.038 \\
\hline
\end{tabular}

${ }^{a} 6 / 11$ women were white

$b_{3}$ FMS subjects had ENF density $<5 \%$ plus abnormal AFT 